\title{
STUDY OF CONFORMATIONAL PREFERENCES OF ERYTHRO- CAROLIGNAN E ASSESSED BY THE COUPLING BETWEEN H7' -H8' IN DIFFERENT NMR SOLVENTS
}

\author{
Rudiyansyah $^{a^{*}, \text { Ajuk Sapar }^{\mathrm{a}} \text {, Masriani }}{ }^{\mathrm{a}}$, Rini Muharini ${ }^{\mathrm{a}}$ and Mary J Garson ${ }^{\mathrm{b}}$ \\ ${ }^{a}$ Jurusan Kimia, Fakultas Matematika dan Ilmu Pengetahuan Alam, Universitas \\ Tanjungpura, Jalan Ahmad Yani, Pontianak 78124, Kalimantan Barat \\ ${ }^{\mathrm{b}} \mathrm{School}$ of Chemistry and Molecular Biosciences, The University of Queensland, Brisbane, \\ QLD 4072 Australia \\ * email: ryansyah_2000@yahoo.co.uk \\ Received 14 April 2014,Accepted 10 July 2014, Published 01 March 2015
}

\begin{abstract}
Erythro-carolignan E (1) has been obtained from the ethanol extract of the wood bark of Durio affinis Becc. This research was conducted in order to prove that conformational preferences of compound 1 were solvent dependent. On the basis of ${ }^{1} \mathrm{H}$ NMR data, the relative configuration of compound 1 was characterized by a coupling constant $\left({ }^{3} J_{\mathrm{HH}}\right)$ value of $3.3 \mathrm{~Hz}$ at $\mathrm{H}-7{ }^{\prime}$ in $\mathrm{CDCl}_{3}$. The coupling constant $\left({ }^{3} J_{\mathrm{HH}}\right)$ values of $\mathrm{H}-$ $7^{\prime}$ in compound 1 has changed to $4.1 \mathrm{~Hz}$ and $5.3 \mathrm{~Hz}$ in pyridine- $d_{5}$ and acetonitrile- $d_{3}$ respectively. As a result, the conformation of compound 1 at C7'-C8' has changed in different NMR solvents. In conclusion, structure of erythro-carolignan $\mathrm{E}$ that contains a dihydroxy group at $\mathrm{C}^{\prime}-\mathrm{C} 8$ ' is able to change in different NMR solvent.
\end{abstract}

Key words: Durio, erythro-Carolignan E, Newman Projection

\section{INTRODUCTION}

Durio or durian, well known as the King of Fruits, has an economic value as a source of timber and fruits. This plant grows only in tropical region of Southeast Asia. Indonesia has 28 species of Durio, of which 19 are endemic species grown in Borneo Island, hence Borneo is known as thecentre of Durio in the world (Subhadrabandhu and Ketsa, 2001; Morton, 1987). Durio affinis is anon-edible fruit species and endemic to Kalimantan. This plant is also known as bird Durio. The wood of D. affinis can be used for making furniture (Uji, 2005).

In previous studies, six carolignan compounds, namely erythro-carolignan E (1), threo-carolignan $\mathrm{E}$, erythro-carolignan $\mathrm{X}$, threo-carolignan $\mathrm{X}$, erythro-carolignan $\mathrm{Y}$ and threo-carolignan Y, have been isolated from the wood bark of D. zibethinus, D. carinatus and D. oxleyanus(Rudiyansyah et al., 2006, 2010; Lim, 2012). Rudiyansyah et al. (2010) have reported the conformational preferences for erythro- and threo-carolignan $\mathrm{X}$ in the NMR solvents $\mathrm{CDCl}_{3}$ and $\mathrm{CD}_{3} \mathrm{OD}$. The conformation for erythro-carolignan $\mathrm{X}$ changed 
from conformer EI to EII (Figure 2) since coupling constant $\left({ }^{3} J_{\mathrm{HH}}\right)$ for proton $\mathrm{H}-7^{\prime}$ changed from $2.6 \mathrm{~Hz}$ in $\mathrm{CDCl}_{3}$ to $6.1 \mathrm{~Hz}$ in $\mathrm{CD}_{3} \mathrm{OD}$.

This research was conducted in order to prove that conformational preferences of compound 1were solvent dependent, which it has been reported previously in literature (Rudiyansyah et al., 2010). As part of our concern in the structures and conformations of carolignans, in this paper, we report the conformation changing for erythro-carolignan $\mathrm{E}$ (1) by studying the coupling constants $\left({ }^{3} J_{\mathrm{HH}}\right)$ of proton $\mathrm{H}-7^{\prime}$ in $\mathrm{CDCl}_{3}$ and other NMR solvents, pyridine- $d_{5}$ and acetonitrile- $d_{3}$. Thus, the conformational preferences for compound 1 will be characterized. In this study, we also isolated other known compounds boehmenan and boehmenan X (Rudiyansyah et al., 2006, 2010, 2014).

\section{METHODS}

\section{Materials}

The wood bark of $D$. affinis Becc.was collected in Arus Deras village, sub-district of Teluk Pakedai, district of Kubu Raya, Province of West Kalimantan in March 2009, air dried, and powdered. The voucher specimens were identified and stored at the Bogoriense Herbarium in Cibinong as 460/IPH.1.02/If.8/V/2009. All solvents were distilled prior to use.

\section{Procedures}

\section{Extraction}

Powdered bark $(5.5 \mathrm{~kg}$ ) of D. affinis was macerated in EtOH ( $3 \times 24$ hours) to provide $341.5 \mathrm{~g}$ of residue $(6.21 \%)$, which was subsequently dissolved in a mixture of $\mathrm{MeOH}-\mathrm{H}_{2} \mathrm{O}(9: 1)$ then partitioned using $n$-hexane $(3 \times 500 \mathrm{~mL})$ and $\mathrm{CHCl}_{3}(3 \times 1500 \mathrm{~mL})$ respectively.

\section{Chromatography}

Thin-layer chromatography (TLC) analysis was performed on pre-coated silica gel plates (Kieselgel $60 \mathrm{~F}_{254}$ or RP-18 $\mathrm{F}_{254 \mathrm{~s}}, 20$ x $20 \mathrm{~cm}, 0.25 \mathrm{~mm}$ thick, Merck). Spots were detected under UV light at $\lambda_{254}$ and $\lambda_{366} \mathrm{~nm}$ or by using $15 \%$ ceric sulfate spray. The $\mathrm{CHCl}_{3}$ extract $(33.2 \mathrm{~g}$ ) was fractionated by VLC (silica gel Kieselgel $60 \mathrm{H}$ ) using a gradient of $n$-hexane-EtOAc (8:2 - 0:10, $\mathrm{MeOH} 100 \%$, each collection was $300 \mathrm{~mL})$ to give seven fractions (DA1 - DA7) on the basis of TLC analyses. Fraction DA7 (14.8 g) was chromatographed further by VLC using a gradient of $n$-hexane-EtOAc (5:5 - 0:10, $\mathrm{MeOH}$ 100\%, each collectionwas $100 \mathrm{~mL}$ ) to obtain eight fractions (DA7a - DA7h). The combined fractions of DA7c and DA7d (505 mg) were fractionated by reverse phase (RP) 
FCC using a gradient of $\mathrm{MeOH}-\mathrm{H}_{2} \mathrm{O}(3: 1,9: 1,10: 0$, each collection was $200 \mathrm{~mL})$ to yield three fractions(DA7cd1 - DA7cd3). Fraction DA7cd1 (176 mg) was fractionated further by normal phase (NP) FCC (silica gel 60; 230-400 mesh) using gradient of $n$-hexane-EtOAc (6:4 - 0:10, each collection was $150 \mathrm{~mL})$ to obtain twenty-seven fractions. Fraction DA7cd1-26 (25 mg) was purified by $\mathrm{C}_{18}$-HPLC (Agilent 1100 series instrument with a variable-wavelength $\mathrm{UV}$ detector, semi-preparative separation used a $\mu$ Bondapak $\mathrm{C}_{18}(7.8$ x $300 \mathrm{~mm}) 10 \mu \mathrm{m}$ column), solvent [ $\mathrm{MeCN}-\mathrm{H}_{2} \mathrm{O}(6: 4, \mathrm{v} / \mathrm{v})$ over 20 minutes, flow rate 1.5 $\mathrm{mL} / \mathrm{min}, \mathrm{UV}$ detection at $254 \mathrm{~nm}$ ] to give compound $\mathbf{1}(2 \mathrm{mg})$.

\section{Structural Elucidation}

The ${ }^{1} \mathrm{H}$ and ${ }^{13} \mathrm{C}$ NMR spectra were recorded either on a Bruker Avance 400 or Bruker Avance 500 spectrometers. ${ }^{1} \mathrm{H}$ NMR spectra were recorded relative to $\mathrm{CDCl}_{3}(\delta=$ $7.24 \mathrm{ppm})$, pyridine- $d_{5}(\delta=7.22 \mathrm{ppm})$ and acetonitrile- $d_{3}(\delta=1.94 \mathrm{ppm})$ respectively, whereas ${ }^{13} \mathrm{C}$ NMR spectra were recorded relative to $\mathrm{CDCl}_{3}(\delta=77 \mathrm{ppm})$. HRESIMS data was measured using a Finnigan MAT 900 XL double focusing magnetic sector mass spectrometer in the positive ion mode. Samples were prepared at a concentration of 10 $\mu \mathrm{M} / \mathrm{ml}$. Specific rotations $[\alpha]_{\mathrm{D}}$ were measured on a Jasco-P2000 spectropolarimeter.

\section{DISCUSSION}

\section{Establishment of structure of erythro-carolignan E}

Compound 1 was obtained as a white amorphous solid. The positive-ion HRESIMS of 1 gave an adduct $[\mathrm{M}+\mathrm{Na}]^{+}$ion at $m / z 753.2524$, corresponding to a molecular formula $\mathrm{C}_{40} \mathrm{H}_{42} \mathrm{O}_{13}$. Compound 1 has a specific rotation $[\alpha]^{25}{ }_{\mathrm{D}}+25.2\left(c 0.15, \mathrm{CHCl}_{3}\right)$. The ${ }^{1} \mathrm{H} \mathrm{NMR}$ spectrum (in $\mathrm{CDCl}_{3}$ ) of $\mathbf{1}$ showed the characteristic ${ }^{1} \mathrm{H}$ NMR signals for two trans-feruloyl groups at $\delta 7.59\left(1 \mathrm{H}, \mathrm{d}, J=15.9 \mathrm{~Hz}, \mathrm{H}-7{ }^{\prime \prime}\right), 6.28\left(1 \mathrm{H}, \mathrm{d}, J=15.9 \mathrm{~Hz}, \mathrm{H}-8{ }^{\prime \prime \prime}\right), 7.01(1 \mathrm{H}, \mathrm{m}$, $J=2.0 \mathrm{~Hz}, \mathrm{H}-2 " '), 7.01$ (1H, m, H-2"'), 6.88 (1H, d, $\left.J=8.2, \mathrm{H}-5{ }^{\prime \prime}\right) 7.05$ (1H, dd, $J=8.2$, $1.9 \mathrm{~Hz}, \mathrm{C}-6 " ')$ and at $\delta 7.49(1 \mathrm{H}, \mathrm{d}, J=15.9 \mathrm{~Hz}, \mathrm{H}-7), 6.21(1 \mathrm{H}, \mathrm{d}, J=15.9 \mathrm{~Hz}, \mathrm{H}-8), 7.00$ $(1 \mathrm{H}, \mathrm{m}, \mathrm{H}-2), 6.90(1 \mathrm{H}, \mathrm{d}, J=8.1 \mathrm{~Hz}, \mathrm{H}-5), 7.02(1 \mathrm{H}, \mathrm{m}, \mathrm{H}-6)$. Furthermore, there were 1,2,3-trioxygenated propanoid signals at $\delta 4.89\left(1 \mathrm{H}, \mathrm{d}, J=3.3 \mathrm{~Hz}, \mathrm{H}-7{ }^{\prime}\right), 4.46(1 \mathrm{H}, \mathrm{m}, \mathrm{H}-$ 8'), 4.25 (1H, m,H-9'a), and 4.44 (1H, m,H-9'b). The ${ }^{1} \mathrm{H}$ NMR spectrum also established the presence of three contiguous methylene groups at $\delta 2.68(2 \mathrm{H}, \mathrm{t}, J=7.3 \mathrm{~Hz}, \mathrm{H}-7 "), 1.99$ $\left(2 \mathrm{H}, \mathrm{m}, \mathrm{H}-8^{\prime \prime}\right)$ and $4.19(2 \mathrm{H}, \mathrm{t}, J=6.5 \mathrm{~Hz}, \mathrm{H}-9 ")$. Two 1,3,4-trisubstituted rings gave resonances at $\delta 6.98\left(1 \mathrm{H}, \mathrm{d}, J=1.8 \mathrm{~Hz}, \mathrm{H}-2^{\prime}\right), 6.95\left(1 \mathrm{H}, \mathrm{d}, J=8.0 \mathrm{~Hz}, \mathrm{H}-5{ }^{\prime}\right), 6.81(1 \mathrm{H}, \mathrm{dd}$, $\left.J=8.0,1.8 \mathrm{~Hz}, \mathrm{H}-6^{\prime}\right)$ for ring A and at $\delta 6.74(1 \mathrm{H}, \mathrm{m}, \mathrm{H}-2 "), 6.85(1 \mathrm{H}, \mathrm{d}, J=8.1 \mathrm{~Hz}, \mathrm{H}-5 ")$, 
$6.72(1 \mathrm{H}, \mathrm{m}, \mathrm{H}-6 ")$ for ring $\mathrm{B}$. There were four methoxy signals at $\delta 3.91\left(3 \mathrm{H}, \mathrm{s}, \mathrm{OCH}_{3}-\right.$ 3"'), $3.90\left(3 \mathrm{H}, \mathrm{s}, \mathrm{OCH}_{3}-3\right), 3.86\left(3 \mathrm{H}, \mathrm{s}, \mathrm{OCH}_{3}-3 "\right)$ and $3.85\left(3 \mathrm{H}, \mathrm{s}, \mathrm{OCH}_{3}-3\right.$ ').

The ${ }^{13} \mathrm{C}$ NMR data at $100 \mathrm{MHz}$ exhibited four methylenes, eighteen methines, fourteen quaternary carbons including two carbonyl resonances at $\delta 167.1(\mathrm{C}-9)$ and 167.3 $\left(\mathrm{C}-9{ }^{\prime \prime \prime}\right)$ and four methoxy carbons at $\delta 55.9\left(\mathrm{OCH}_{3}-3{ }^{\prime \prime \prime} / \mathrm{OCH}_{3}-3 / \mathrm{OCH}_{3}-3\right)$ and at $\delta 56.8$ (OMe-3"). All of these data were consistent with erythro-carolignan E (Figure 1) in which this compound has been previously reported by Rudiyansyah etal., (2010), Huang et al., (2012),Paula et al.,(1995) and by Wu et al., (2005). The relative configuration of 1 was elucidated by a triplet signal for $\mathrm{H}-7$ ' with a coupling constant of $3.3 \mathrm{~Hz}$ (in $\mathrm{CDCl}_{3}$ ) which is diagnostic of an erythro diastereomer (Braga et al., 1984).

\section{Conformational Preferences of erythro-carolignan E}

Braga et al., (1984) stated that the erythro isomer would have $3.2 \mathrm{~Hz}$ coupling since intramolecular hydrogen bonding would favour conformation EI (Figure 2). Braga also noted that conformer EIII, in which the hydrogens are also gauche, might contribute to the conformational equilibria for the erythro compound. Moreover, Karplus(1963) mentioned that the coupling constant between $\mathrm{H}-7^{\prime}$ and $\mathrm{H}-8$ ' could be used to determine the conformation around the C-7'/C-8' bond. Furthermore, Bifulco et al.,(2007) stated that the conformational relationship in acyclic systems between adjacent stereocentres is explained by staggered conformers. Additionally, Riccio et al., (2003) and Matsumoriet al., (1999) have developed a method to determine the relative configuration of acyclic compounds on the basis of proton-proton coupling constants together with proton-carbon coupling constants. For erythro compounds with $\mathrm{C}_{7} \mathrm{C}_{8}$-dioxy substituents, the vicinal coupling constants in an individual rotamer can be in the range $0-4 \mathrm{~Hz}$ (gauche) or 7-10 Hz (anti); these values are described as small or large, respectively.

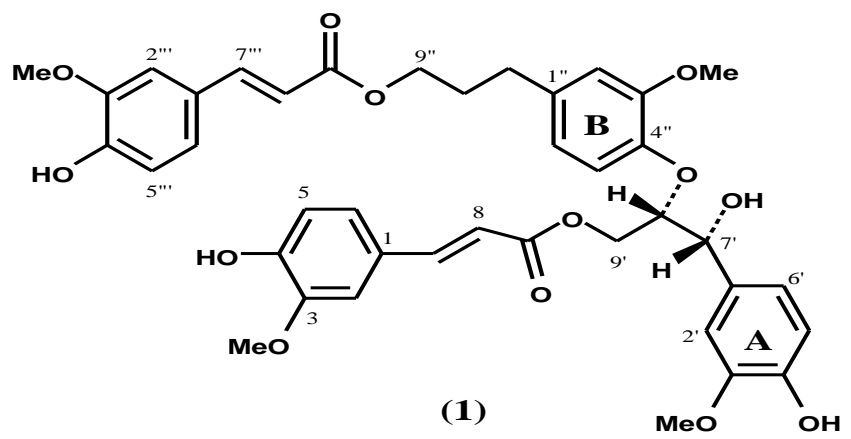

Figure 1. Structure of compound 1

Consequently, in compound $\mathbf{1}$, the hydrogen bonding effect forces the erythro isomer to adopt conformation EI and EIIIin which the hydrogens are gauche, hence the $3.3 \mathrm{~Hz}$ 
coupling that was observed. Moreover, conformer EII is reasonable since the bulky substituents are separated and dipole effects are minimized. Based on a ${ }^{3} J_{\mathrm{HH}}$ value, it is clear that the hydrogen bonding effect dictates the conformational preferences, thus EI and EIII are the predominant conformers for the erythro compound $\mathbf{1}$.

From our previous study, the NMR data for erythro-carolignan $\mathrm{X}$ were solvent dependent. When the NMR spectrum of the erythro compound was re-run in $\mathrm{MeOH}-d_{4}$, a coupling constant of proton $\mathrm{H}-7^{\prime}$ changed from $2.6 \mathrm{~Hz}$ to $6.1 \mathrm{~Hz}$ (Rudiyansyah et al., 2010). These data suggested a change in conformation for the erythro compound.

Recent study also proved that the conformation of compound $\mathbf{1}$ changed when the spectral data were run in either pyridine- $d_{5}$ or acetonitrile- $d_{3}$. In acetonitrile- $d_{3}$, with a coupling constant of $5.3 \mathrm{~Hz}$, the hydroxyl group is now hydrogen-bonded to the solvent in preference to the adjacent OAryl group.

Conformational preferences will be decided by steric effects and by dipole repulsion effects. Consequently conformer EII in which the $\mathrm{H}-7^{\prime} / \mathrm{H}-8^{\prime}$ is diaxial will be important. On the other hand, in pyridine- $d_{5}$, a coupling constant of $4.1 \mathrm{~Hz}$ was found, indicating that the Newman projection has changed insignificantly. Compound $\mathbf{1}$ both in $\mathrm{CDCl}_{3}$ and pyridine- $d_{5}$ showed similar coupling constants that were $3.3 \mathrm{~Hz}$ and $4.1 \mathrm{~Hz}$ respectively.
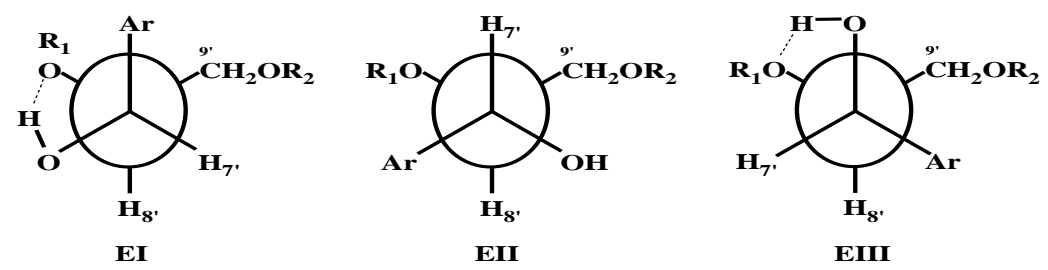

Figure 2. Three possible conformers for compound $\mathbf{1}$

This study showed that it was important to consider solvent effects on conformational preferences when determining relative configuration. The value of the coupling constant $\left({ }^{3} J_{\mathrm{H} 7}\right.$-H8 $)$ for erythro-carolignan $\mathrm{E}$ (1) differed in different NMR solvents. In order to study more about preferred conformation for erythro compounds, ${ }^{1} \mathrm{H}$ NMR experiment in cool condition should be conducted. Recently, Ardá et al., (2010) have measured the ${ }^{3} J_{\mathrm{HH}}$ coupling by doing low-temperature NMR analysis of flexible acyclic systems in order to get the existence of multiple conformer. Other chemical structures from this plant, boehmenan and boehmenan $X$, were also characterized by comparison between their spectroscopic data with data from the literature [Rudiyansyah et al., 2014; Paula et al., 1995; Secaet al., 2001). 


\section{CONCLUSIONS}

A lignan, namely erythro-carolignan E (1) have been isolated and characterized by ${ }^{1} \mathrm{H}$ and ${ }^{13} \mathrm{C}$ NMR including HRESIMS. The relative configuration of compound $\mathbf{1}$ was determined from the coupling constant of $\mathrm{H}-\mathrm{7}^{\prime}$ and $\mathrm{H}-8$ ' that was $3.3 \mathrm{~Hz}$. A structure of erythro-carolignan $\mathrm{E}$ that contains a dihydroxy group at $\mathrm{C}^{\prime}-\mathrm{C} 8$ ' is able to interchangeable in different NMR solvent.

\section{ACKNOWLEDGEMENT}

This study was supported by a fundamental research grant, funded by the Ministry of Education and Culture, Indonesia, No. 183/SP2H/PL/E.5.2/DITLITABMAS/IV/2011. We also thank Mr. G. Mcfarlane for HRESIMS, the staff of the Bogoriense Herbarium, Cibinong, Indonesia, for identification of plant material, Dr. Tri Le for NMR measurements.

\section{REFERENCE}

Ardá, A., Nieto, M.S., Blanco, M., Jiménez, C., Rodríguez, J., 2010, Low-Temperature NMR J-Based Configurational Analysis of Flexible Acyclic Systems, Journal of Organic Chemistry, vol. 75, pp. 7227-7232.

Bifulco, G., Dambruoso, P., Gomez-Paloma, L., Riccio, R., 2007, Determination of Relative Configuration in Organic Compounds by NMR Spectroscopy and Computational Methods, Chemical Reviews, vol. 107, pp. 3744-3779.

Braga, A.C.H., Zacchino, S., Badano, H., Sierra, M.G., Rúveda, E.A., 1984, ${ }^{13}$ C NMR Spectral And Conformational Analysis of 8-O-4' Neolignans, Phytochemistry, vol. 23, pp. 2025-2028.

Huang, H.C., Chiou, C. T., Hsiao, P.C., Liaw, C.C., Zhang, L.J., Chang, C.L., Chen, I.S., Chen, W.C., Lee, K.H., Kuo, Y.H., 2012, Cytotoxic Phenylpropanoids and a New Triterpene, Turformosinic Acid, from Turpiniaformosana Nakai, Molecules, vol. 17, pp. 1837-1851.

Karplus, M., 1963, Vicinal Proton Coupling in Nuclear Magnetic Resonance, Journal of The American Chemical Society, vol. 85, pp. 2870-2871.

Lim, T.K., 2012, Edible Medicinal and Non-Medicinal Plants: Fruits, vol. 1, Springer Publisher, New York, pp. 563-565.

Matsumori, N., Kaneno, D., Murata, M., Nakamura, H., Tachibana, K., 1999, Stereochemical Determination of Acyclic Structures Based on Carbon-Proton Spin-Coupling Constants. A Method of Configuration Analysis for Natural Products, Journal of Organic Chemistry, vol. 64, pp. 866-876.

Morton, J.F., 1987, Fruits of Warm Climates: Durian, Miami, FL,Creative Resource System Inc, pp. 287-291. 
Paula, V.F., Barbosa, L.C.A., Howarth, O.W., Demuner, A.J., Cass, Q.B., Vieira, I.J.C., 1995, Lignans from Ochroma lagopus Swartz, Tetrahedron, vol.51, pp. 1245312462.

Riccio, R., Bifulco, G.,Cimino, P.,Bassarello, C., Gomez-Paloma,L., 2003, Stereochemical Analysis Of Natural Products: Approaches Relying On The Combination Of NMR Spectroscopy and Computational Methods, Pure and Applied Chemistry, vol. 75, pp. 295-308.

Rudiyansyah,Garson, M.J., 2006, Secondary Metabolites From The Wood Bark Of Durio Zibethinus and Durio Kutejensis, Journal of Natural Products, vol, 69, pp. 12181221.

Rudiyansyah, Lambert, L.K. Garson, M.J., 2010, Lignans And Triterpenes From The Bark Of Durio Carinatus and Durio Oxleyanus, Journal Of Natural Products, vol. 73, pp. 1649-1654.

Rudiyansyah, Masriani, Mudianta, I.W., Garson, M.J., 2014, Isolation and Absolute Configuration of Boehmenan from Durio affinis Becc.,Records of Natural Products, vol. 8, pp. 195-198.

Seca, A.M.L., Silva, A.M.S., Silvestre, A.J.D., Cavaleiro, J.A.S., Domingues, F.M.J., Pascoal-Neto, C., 2001, Phenolic Constituents From The Core Of Kenaf (Hibiscus cannabinus), Phytochemistry, vol. 56, pp. 759-767.

Subhadrabandhu, S.,Ketsa, S., 2001, Durian King Of Tropical Fruit, CABI publishers, Wellington New Zealand, 2001, pp. 1-5.

Uji, T., 2005, Keanekaragaman Jenis dan Sumber Plasma Nutfah Durio(Duriospp.) di Indonesia, Bulletin Plasma Nutfah, vol. 11, pp. 28-33.

Wu, P.L., Wu, T.S., He, C.X., Su, C.H., Lee, K.H., 2005, Constituents from The Stems of Hibiscus Taiwanensis, Chemical and Pharmaceutical Bulletin, vol. 53, pp. 56-59. 